\title{
DEGRADATION BEHAVIOR OF COATINGS FORMED BY THE PLASMA ELECTROLYTIC OXIDATION TECHNIQUE ON AZ61 MAGNESIUM ALLOYS CONTAINING 0, 1 AND 2 WT\% CA
}

\author{
Anawati ${ }^{*}$, Hidetaka Asoh ${ }^{2}$, Sachiko Ono ${ }^{2}$ \\ ${ }^{1}$ Department of Physics, Faculty of Mathematics and Natural Sciences, Universitas Indonesia, \\ Kampus UI Depok, Depok 16424, Indonesia. \\ ${ }^{2}$ Department of Applied Chemistry, Kogakuin University, 2665-1 Nakano, Hachioji, Tokyo, Japan
}

(Received: September 2017 / Revised: January 2018 / Accepted: March 2018)

\begin{abstract}
The characteristics of coatings formed by Plasma Electrolytic Oxidation (PEO) are affected by the composition of metal substrates. In this work, the effect of alloying element $\mathrm{Ca}(0,1$ and 2 $w t \%)$ on the degradation behavior and apatite-forming ability of PEO coated AZ61 magnesium alloys was clarified by means of polarization measurements in $0.9 \% \mathrm{NaCl}$ solution and an invitro test in Simulated Body Fluid (SBF), respectively. The AZ61 alloys were subjected to plasma electrolytic oxidation at a constant current of $200 \mathrm{~A} / \mathrm{m}^{2}$ at $25^{\circ} \mathrm{C}$ for $8 \mathrm{~min}$ in $0.5 \mathrm{M}$ $\mathrm{Na}_{3} \mathrm{PO}_{4}$ solution. The surface investigation suggested no significant effect of $\mathrm{Ca}$ content on the morphology of the PEO coating formed on the AZ61 specimens. The coatings exhibited an eruption-like structure decorated with micropores and microcracks. Their average thicknesses were 13.2, 17.4 and $14.3 \mu \mathrm{m}$ for AZ61, AZ61-1Ca and AZ61-2Ca, respectively. The polarization measurements showed no significant difference in the corrosion potentials $(-1.60$ $\mathrm{VAg} / \mathrm{AgCl})$ and corrosion current densities $\left(1.61 \times 10^{-5} \mathrm{~A} \mathrm{~cm}^{-2}\right)$ of all the coated specimens. Similarly, there was no significant effect of $\mathrm{Ca}$ on the apatite-forming ability in SBF, as indicated by the lack of apatite deposition on all the coated specimens after 14 days of immersion. Further sealing of the PEO coatings by chemical treatment in $\mathrm{NaOH}$ solution is suggested to enhance the corrosion resistance.
\end{abstract}

Keywords: Anodization; Coating; Corrosion; Magnesium; PEO

\section{INTRODUCTION}

There has been great interest in adding calcium (Ca) as an alloying element to magnesium $(\mathrm{Mg})$ and its alloys to enhance the corrosion resistance of $\mathrm{Mg}$ alloys for both engineering material and biomaterial applications. The addition of Ca not only enhances the corrosion resistance but also the burning and creep resistance of Mg alloys (Qudong et al., 2001), which is advantageous for engineering applications. As well as engineering applications, $\mathrm{Mg}$ and its alloys have been considered as potential candidates for biodegradable implant material, considering their instantaneous degradation in physiological solution, high biocompatibility and suitable mechanical properties (Song, 2007; Witte et al., 2008; DeGarmo, 2011). The main challenge to their application as a biodegradable material is control of the degradation rate, which is still considered to be high. Alloying with $\mathrm{Ca}$ is expected to reduce the degradation rate, as well as accelerating the growth of bone mineral hydroxyapatite (HA).

\footnotetext{
*Corresponding author's email: anawati@sci.ui.ac.id, Tel: +62-21-7872609, Fax. +62-21-7863441

Permalink/DOI: https://doi.org/10.14716/ijtech.v9i3.712
} 
Salashoor \& Guo (2012) reported that when a Ca concentration was added to Mg metal below the solubility limit, the corrosion resistance of $\mathrm{Mg}$ alloys increased with the $\mathrm{Ca}$ content. However, above the solubility limit, $\mathrm{Ca}$ had a negative effect on the corrosion resistance of binary $\mathrm{MgCa}$ alloys. The phase diagram of binary $\mathrm{Mg}-\mathrm{Ca}$ indicates that the maximum solubility of $\mathrm{Ca}$ in $\mathrm{Mg}$ is $~ 1.34$ wt\% (Massalski, 1990). In $\mathrm{Mg}$-Al series, $\mathrm{Ca}$ acts as a grain refinement when added to the alloys, by forming precipitation of $\mathrm{Al}_{2} \mathrm{Ca}$ and $\mathrm{Mg}_{2} \mathrm{Ca}$, and reducing the $\mathrm{Mg}_{17} \mathrm{Al}_{12}$ phase at the grain boundaries (Kannan \& Raman, 2008; Srinivasan et al., 2010; Gu et al., 2011). The grain boundary precipitates enhances the corrosion resistance of cast AZ61 and AZ91 when alloyed with 1 and 0.4 wt\% Ca respectively (Kannan \& Raman, 2008). Precipitation of second phases in $\mathrm{Mg}$ alloys has a dual role in the corrosion process (Lunder, 1997; Atrens et al., 2011). When the phases segregates continuously along the grain boundaries forming a network, they acts as a corrosion barrier, preventing corrosion to cross the neighboring grains. On the other hand, if the phases exists as discrete particles, they accelerates corrosion in the surrounding metal matrix.

Although $\mathrm{Ca}$ has a beneficial effect on the bioactivity of $\mathrm{Mg}$ alloys, alloying $\mathrm{Mg}$ with $\mathrm{Ca}$ is sometimes not sufficient to reduce the degradation rate significantly in an aqueous solution. A combination of alloying and surface treatment is often required to gain significant improvement in the corrosion resistance of $\mathrm{Mg}$ alloys. Application of a coating is a simple way to create a barrier between a metal substrate and its environment, thus reducing corrosion activity. The ability of Plasma Electrolytic Oxidation (PEO) to form a hard coating on $\mathrm{Mg}$ alloys has been extensively studied (Rakoch et al., 2006; Hussein et al., 2013; Anawati et al., 2017; Ceschini et al., 2017). PEO is an electrochemical anodization technique to form a coating layer on a metal substrate by applying a high potential above the breakdown voltage to generate an intense plasma, which leads to a robust oxidation of the metal surface. The metallic surface is converted into a ceramic oxide layer during the PEO process. The resulting coating layer exhibits high wear and corrosion resistance (Srinivasan et al., 2010; Gu et al., 2011; Hussein et al., 2013). Cracks are typically observed in the PEO layer on $\mathrm{Mg}$ alloys due to large differences in the volume ratio between the oxide layer and the metal substrate (Rakoch, 2006). The coating characteristics are determined by the electrolyte, alloy properties and processing parameters, such as anodization time and potential (Hornberger et al., 2012). Most work has focused on the effect of the processing parameters, but there has been a lack of findings on the effect of alloy composition on the PEO coating properties. In this work, the effect of the alloying element $\mathrm{Ca}$ on the corrosion behavior and the apatite-forming ability of AZ61 alloys is investigated.

\section{METHODOLOGY}

\subsection{Materials}

The material used in this work was commercial rolled plate AZ61 alloys containing 0,1 and 2 wt $\% \mathrm{Ca}$, with a thickness of $1 \mathrm{~mm}$. The main alloying elements of AZ61 were $6 \mathrm{wt} \%$ aluminum $(\mathrm{Al})$ and $1 \mathrm{wt} \% \mathrm{zinc}(\mathrm{Zn})$. The plates were cut into $3 \mathrm{~cm} \times 3 \mathrm{~cm}$ specimens.

\subsection{Anodization}

Prior to anodization, the specimens were chemically treated in $8 \mathrm{vol} \% \mathrm{HNO}_{3}-1 \mathrm{vol} \% \mathrm{H}_{3} \mathrm{PO}_{4}$ for $20 \mathrm{~s}$ followed by immersion in $5 \mathrm{wt} \% \mathrm{NaOH}$ solution at $80^{\circ} \mathrm{C}$ for $1 \mathrm{~min}$. Anodization was conducted by a PEO technique at a constant current of $200 \mathrm{~A} / \mathrm{m}^{2}$ at $25^{\circ} \mathrm{C}$ for $8 \mathrm{~min}$ in $0.5 \mathrm{M}$ $\mathrm{Na}_{3} \mathrm{PO}_{4}$ solution. Some of the coated AZ61-2CA specimens were further treated in $0.25 \mathrm{M}$ $\mathrm{NaOH}$ solution at $80^{\circ} \mathrm{C}$ for $90 \mathrm{~min}$, with the main purpose being to seal the coating (Anawati et al., 2015).

\subsection{Corrosion Test}

The electrochemical corrosion behavior was established by performing potentiodynamic polarization tests in $0.9 \% \mathrm{NaCl}$ solution at $37^{\circ} \mathrm{C}$ based on ASTM G5. The potential was swept 
from -1.7 to $1.2 \mathrm{~V}_{\mathrm{Ag} / \mathrm{AgCl}}$ at the rate of $0.1 \mathrm{mV} / \mathrm{s}$ by using a potentiostat (Ivium). Three configurations of electrodes were used for the test. A platinum coil was used as a counter electrode and silver/silver chloride was used as the reference electrode.

\subsection{In Vitro Immersion Test}

The bioactivity or apatite-forming ability of the coated specimens was studied by an in vitro test in SBF at $37^{\circ} \mathrm{C}$ for 14 days. The SBF was prepared based on the work of Muller and Muller (2006) and the ionic composition is listed in Table 1. The solution was refreshed after 3, 5, 7, 10, and 12 days. After the test, the specimens were rinsed thoroughly in DI water and then dried in an air stream.

Table 1 Ionic concentration of SBF

\begin{tabular}{ccccccccc}
\hline Ion & $\mathrm{Na}^{+}$ & $\mathrm{K}^{+}$ & $\mathrm{Mg}^{+}$ & $\mathrm{Ca}^{+}$ & $\mathrm{Cl}$ & $\mathrm{HCO}_{3}^{-}$ & $\mathrm{HPO}_{4}^{2-}$ & $\mathrm{SO}_{4}^{2-}$ \\
\hline Concentration $(\mathrm{mM})$ & 142 & 5 & 1 & 2.5 & 126 & 10 & 1 & 1 \\
\hline
\end{tabular}

\subsection{Characterization}

The coating thickness was measured by a coating thickness gauge (Sanko). Surface morphology before and after the corrosion test was investigated by using FE-SEM (JEOL JSM06701). The crystalline phases in the coated specimens after the bioactivity test were detected by X-Ray Diffraction analysis (XRD, Rigaku Rint 2000).

\section{RESULTS AND DISCUSSION}

We have previously reported the characterization results of the PEO coatings formed on AZ61, AZ61-1Ca and AZ61-2Ca specimens (Anawati \& Gumelar, 2017). The coatings had an uneven structure decorated with micrometer sized voids and cracks. There was no significant difference in the chemical composition and morphology of the coatings formed on the three specimens. The coatings were composed of crystalline $\mathrm{Mg}_{3}\left(\mathrm{PO}_{4}\right)_{2}$, as detected by an X-Ray Diffractometer (XRD), mixed with the amorphous phases. No Ca compound was detected by XRD, but might exist in the amorphous state. Similarly, earlier work (Anawati et al., 2017) on PEO coating grown on AM60 containing 0-2 wt\% Ca alloys suggested the presence of Ca compound in an amorphous state incorporated in the coatings, as proven by depth profile of the Glow Discharge Optical Emission Spectroscopy (GDOES), while the XRD analysis showed no indication of Ca in the crystalline phase. Moreover, the concentration of $\mathrm{Ca}$ in the AZX alloys was too low to supply significant incorporation in the coatings. X-Ray Fluorescence (XRF) spectroscopy detected a high concentration of $\mathrm{Zn}$ in the coatings. The concentrations formed on AZ61, AZ61-1Ca and AZ61-2Ca were 30.8, 29.9 and 24.4 wt\%, respectively. Zn probably existed in the form of amorphous compounds, as these were not detected by XRD. Other than Zn, XRF detected a high concentration of $\mathrm{Mg}$ and $\mathrm{P}$ in the range of $30-50 \%$ for $\mathrm{Mg}$, and $20-30 \mathrm{wt} \%$ for $\mathrm{P}$, while $\mathrm{O}$ concentration was in the range of 3-4 wt\%, which matched the XRD results well. The mechanical hardness of the three specimens was similar, in the range of 123-124 HV, which was twice the hardness of the substrates. In this work, the degradation behavior of the coatings is reported.

\subsection{Coating Appearance and Thickness}

The anodization curves reported earlier (Anawati \& Gumelar, 2017) indicated that for an identical anodization time there was a tendency for the coating thickness to increase slightly in line with the $\mathrm{Ca}$ concentration in the alloys, owing to the extension of fine plasma life-time during anodization, but the increment was insignificant. Figure 1 shows the PEO coating appearance and the thickness formed on the AZ61, AZ61-1Ca and AZ61-2Ca specimens. All 
the coatings showed a similar matte white appearance. The average thicknesses as measured by the coating thickness gauge were 13.2, 17.4 and $14.3 \mu \mathrm{m}$ for the AZ61, AZ61-1Ca and AZ61$2 \mathrm{Ca}$ specimens respectively. The presence of $\mathrm{Ca}$ tended to increase the coating thickness. The error bar for the AZ61-1Ca data in Figure 1b is quite large, which might indicate that a higher surface roughness was obtained relative to the other two specimens.

All of the specimens showed similar coating morphology, regardless of the Ca content in the alloys (Figure 2). The coatings exhibited a non-uniform structure, eruption-like with hills and craters, as shown in the cross-section images in Figure 2. Cracks and voids appeared both on the surfaces and in the cross-section parts. However, neither the cracks nor voids penetrated through the substrate. From a thermodynamic viewpoint, the Pilling-Bedworth ratio of oxides formed on $\mathrm{Mg}$ alloys, which includes $\mathrm{MgO}, \mathrm{Mg}(\mathrm{OH})_{2}$ and $\mathrm{MgPO}_{4}$ have ratios greater than 2, indicating vulnerability to cracks due to volume expansion of the grown oxide. It is suggested that the voids were formed as a result of the entrapment of gas which was evolved during metal oxidation in the molten oxide.

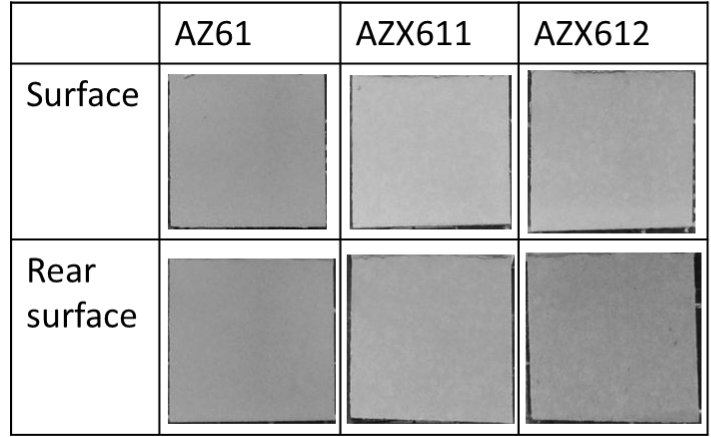

a)

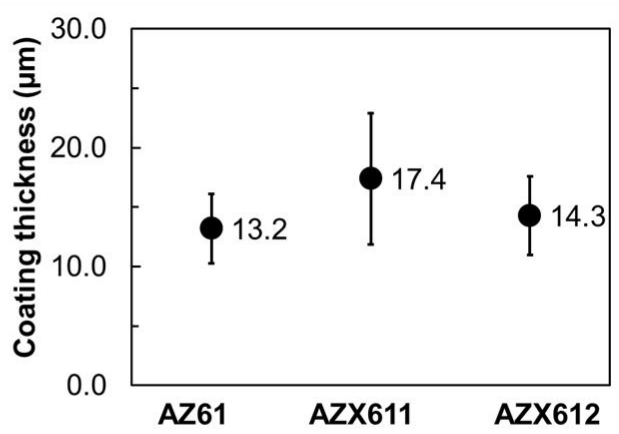

b)

Figure 1 (a) PEO coating appearance; and (b) the corresponding coating thickness formed on AZ61, AZ61-1Ca, and AZ61-2Ca specimens
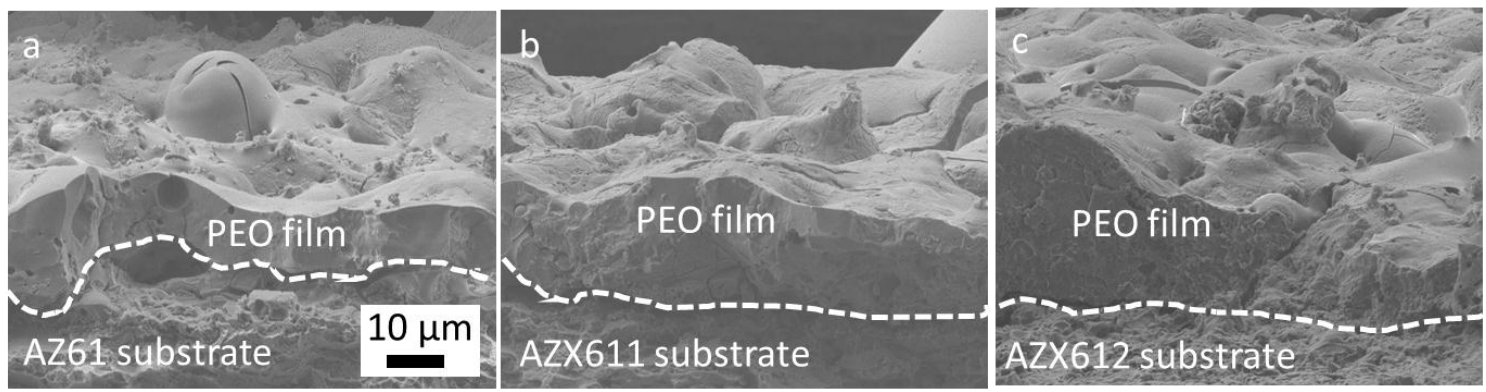

Figure 2 Cross-section FESEM images showing the morphology of the coatings formed on: (a) AZ61; (b) AZ61-1Ca; and (c) AZ61-2Ca specimens

\subsection{Electrochemical Corrosion}

The electrochemical corrosion behavior of the coated AZ61, AZ61-1Ca and AZ61-2Ca specimens is presented in the polarization curves in Figure 3. The curves of the three specimens nearly overlap with each other, indicating no significant difference in their electrochemical behavior. The corrosion potential and current density of the specimens was determined from the polarization curve by the Tafel extrapolation method. The corrosion potential of the coated AZ61 and AZ61-2Ca was similar at $-1.60 \mathrm{~V}_{\mathrm{Ag} / \mathrm{AgCl}}$, while slightly higher at $-1.57 \mathrm{~V}_{\mathrm{Ag} / \mathrm{AgCl}}$ for AZ61-1Ca. The corrosion potential of the coated specimens was close to that of uncoated pure $\mathrm{Mg}$ (Anawati et al., 2015). The Mg phase at the metal-coating interface was selectively 
corroded during the polarization test following the mechanism for coating penetration in Figure 4. The corrosion current density for the three specimens was similar at $1.61 \times 10^{-5} \mathrm{~A} \mathrm{~cm}^{-2}$. Moreover, all the coated specimens exhibited similar pitting potential, at $-1.47 \mathrm{~V} \mathrm{Ag} / \mathrm{AgCl}$.

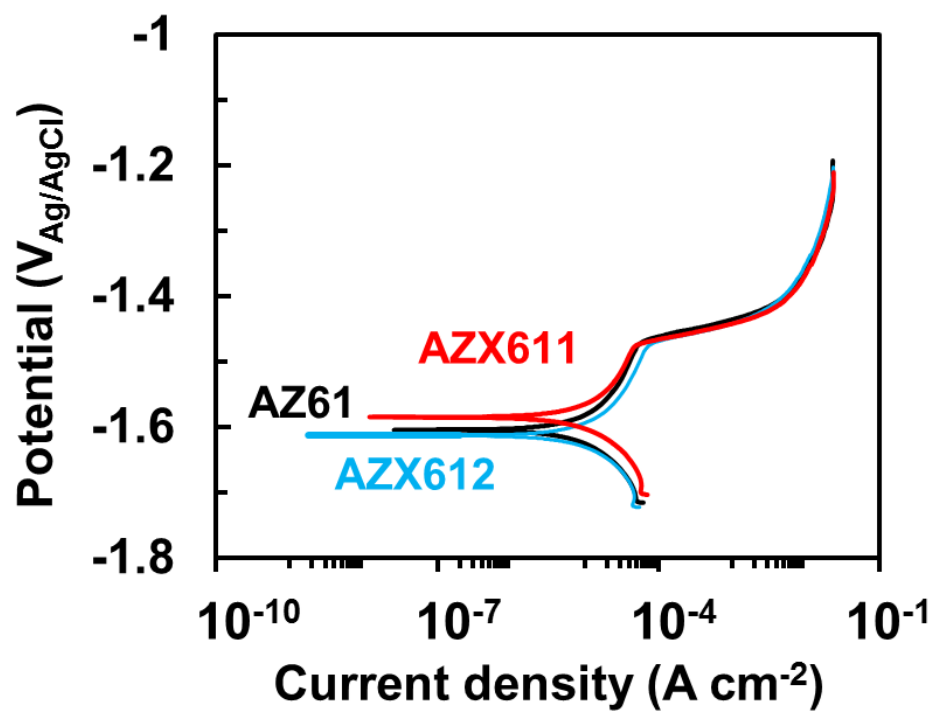

Figure 3 Potentiodynamic polarization curves of coated AZ61, AZ61-1Ca, and AZ61-2Ca in $0.9 \% \mathrm{NaCl}$ solution at $37^{\circ} \mathrm{C}$

The polarization curves suggest that under applied potentials the three coated specimens generated similar current density outputs. In other words, the degree of protection provided by the coating in $\mathrm{NaCl}$ solution was similar. The presence of $\mathrm{Ca}$ as an alloying element in AZ61 alloys did not alter the corrosion behavior of the coated specimens when the test solution contained only $\mathrm{Na}^{+}$and $\mathrm{Cl}^{-}$ions.

\subsection{In Vitro Bioactivity Test}

The surface morphology of the coated specimens before and after 14 days of immersion in SBF is shown in Figure 4. All the as-coated specimens exhibited similar rough morphology, regardless of the Ca content in the alloys, as shown in Figures 4a to 4c. After a 14 day in vitro test in SBF, the coated AZ61 specimen showed mild coating deterioration in a few micrometer sized spots, as indicated by the black circles in Figure 6d. While no visible cavity was observed on the AZ61 specimen, both the AZ61-1Ca and AZ61-2Ca specimens had large cavities at the specimen center. The specimen damage caused by corrosion was bigger and deeper in AZ612Ca than in the AZ61-1Ca specimens. The cavity in the AZ61-1Ca specimen seemed to be elongated approaching the specimen edge, while the cavity formed in the AZ61-2Ca specimen (Figure 4f) was bigger, at about $1 \mathrm{~mm}$. The results infer that the deterioration of the coated specimen increased with increasing $\mathrm{Ca}$ content in the alloys after long term exposure in SBF. The reason for such behavior is still not clear.

The bioactivity of a biodegradable material is identified by the formation of a bone mineral apatite. Figure 5 shows the XRD pattern of the coated specimens after immersion in SBF for 14 days. The pattern shows a similar phase of $\mathrm{Mg}_{3}\left(\mathrm{PO}_{4}\right)_{2}$, as observed on the specimens before immersion. There was no additional peak for apatite in the curves of any of the specimens. The results suggest that none of the specimens showed any bioactivity. An immersion time longer than 14 days was probably required for deposition of apatite on the coated AZ61 specimen. However, since rapid metal dissolution occurred in the AZ61-1Ca and AZ61-2Ca specimens during immersion, apatite formation was somewhat difficult in these cases. The high material dissolution inhibited deposition of insoluble apatite on the surface. The SEM images in Figure 4 
confirm no apatite layer formed on the specimen surfaces after the immersion test and therefore simultaneous material dissolution occurred during the test. Apatite formation is known to provide a barrier for the underlying material (Song, 2007).
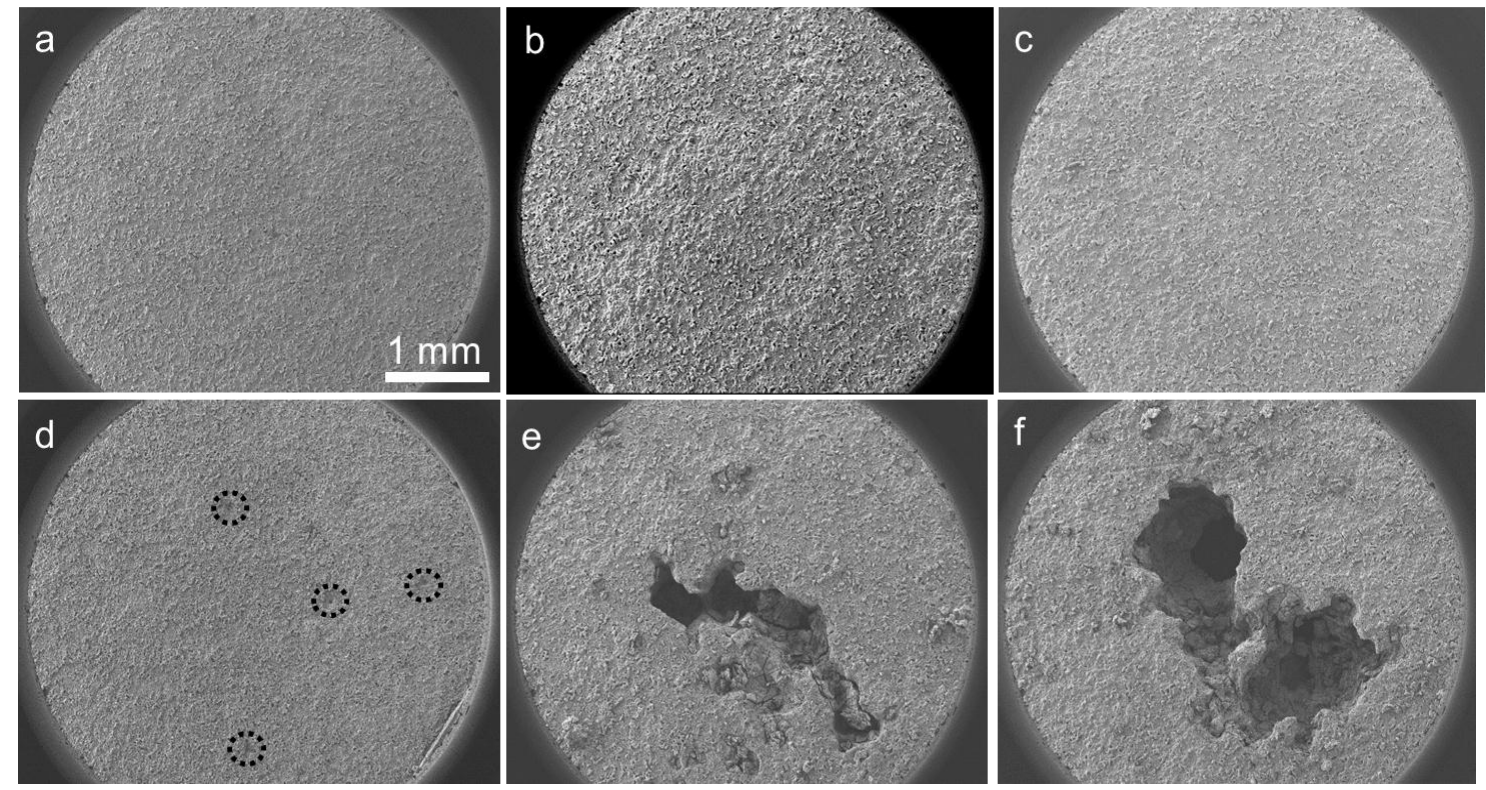

Figure 4 Surface morphology (a)-(c) before and (d)-(f) after immersion in SBF at $37^{\circ} \mathrm{C}$ for 14 days of coated (a) and (d) AZ61; (b) and (e) AZ61-1Ca; and (c) and (f) AZ61-2Ca specimens

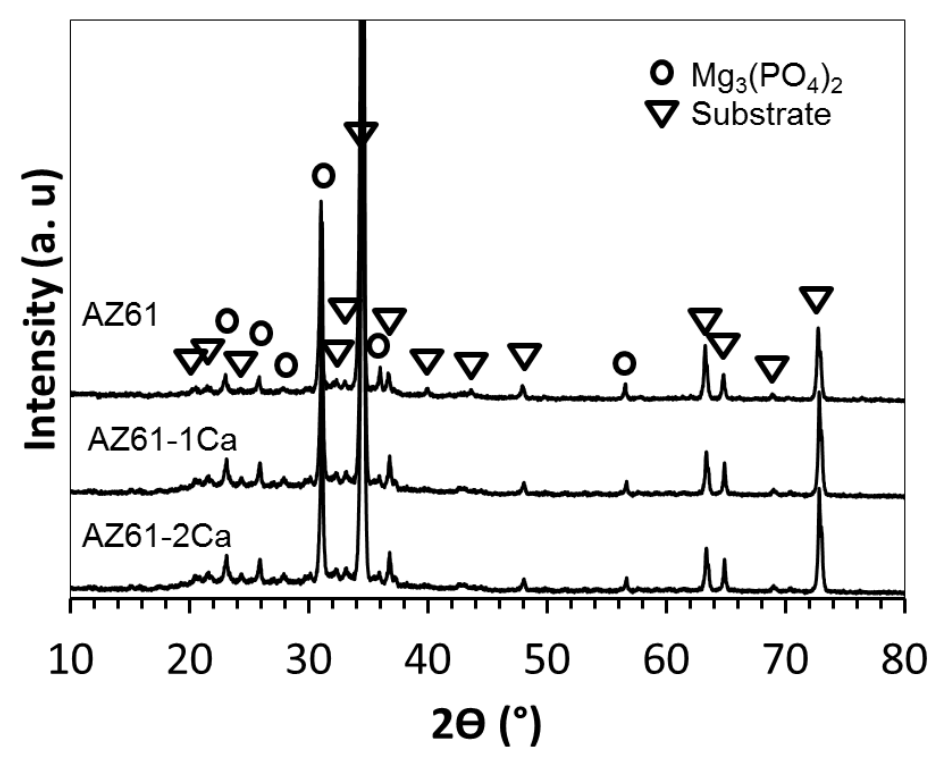

Figure 5 XRD pattern of the coated AZ61, AZ61-1Ca, and AZ61-2Ca specimens after immersion in $\mathrm{SBF}$ at $37^{\circ} \mathrm{C}$ for 14 days

The proposed mechanism of coating deterioration and corrosion propagation is presented schematically in Figure 6. At the initial immersion time, thinning of the coating occurred and a significant amount of coating layer dissolved in the solution. The solution also penetrated the metal substrate through cracks and defects in the coating. The metal substrate under the coating therefore underwent local corrosion, creating pouches at the metal-coating interface. Typical corrosion for coated specimens is crevice and pitting corrosion ( $\mathrm{Gu}, 2011)$. As corrosion propagated laterally, the pouches grew larger, with deeper undermining of the coating, which 
further led to the detachment of the coating layer in the vicinity of the corroded areas. Once the metal substrate was exposed to the solution, corrosion proceeded continuously, deep into the bulk metal.

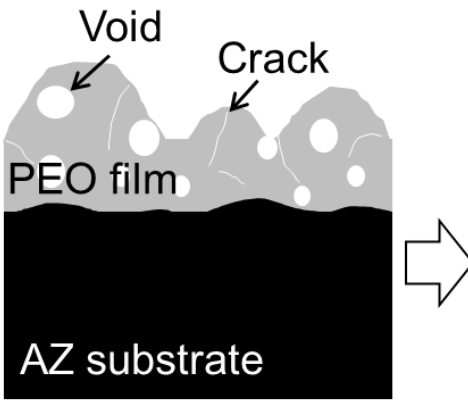

As-coated

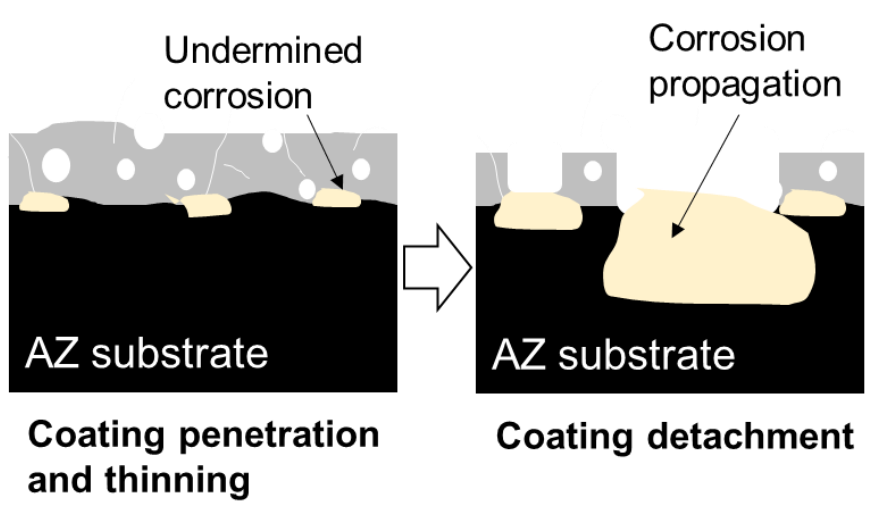

Figure 6 Schematic diagram of PEO coating degradation during the corrosion test

\subsection{Effect of Sealing on the Polarization Curve}

To improve the performance of the coating, it was sealed in a hot alkaline solution. The main purpose was to seal the exposed substrate at the cracks and defects in the coating. The coated AZ61-2Ca specimen was treated with $\mathrm{NaOH}$ solution. The alkaline treatment did not change the coating thickness or microstructure significantly, as shown in Figure 7a. However, it changed the nanostructure of the outer coating surface, as can be seen in the inset image in Figure 7a. A nanosheet structure of about one micron in depth had formed on the coating surfaces. From a thermodynamic viewpoint, in an alkaline environment $\mathrm{Mg}(\mathrm{OH})_{2}$ is the stable phase that is formed on Mg alloys. Previous work by Anawati et al. (2015) also reported that such a nanosheet structure formed on a PEO coating composed of magnesium hydroxide, $\mathrm{Mg}(\mathrm{OH})_{2}$. After alkaline treatment, both the coating and exposed metal surfaces were covered with a $\mathrm{Mg}(\mathrm{OH})_{2}$ layer. Figure $6 \mathrm{~b}$ shows the polarization curve of the coated AZ61-2Ca specimen after sealing, compared to that before sealing. The polarization curve of the as-coated specimen notably shifted to the nobler direction after sealing. The corrosion potential became $1.35 \mathrm{~V} \mathrm{Ag/AgCl}$, which was $250 \mathrm{mV}$ higher than that of the as-coated one. The corrosion current density after sealing was $1.56 \times 10^{-7} \mathrm{~A} \mathrm{~cm}^{-2}$, which was two order magnitudes lower than that of as-coated specimen. Significant improvement in the corrosion resistance of the PEO coated specimen was obtained by sealing in an alkaline solution. The in vitro bioactivity of the sealed specimens in SBF will be studied further.
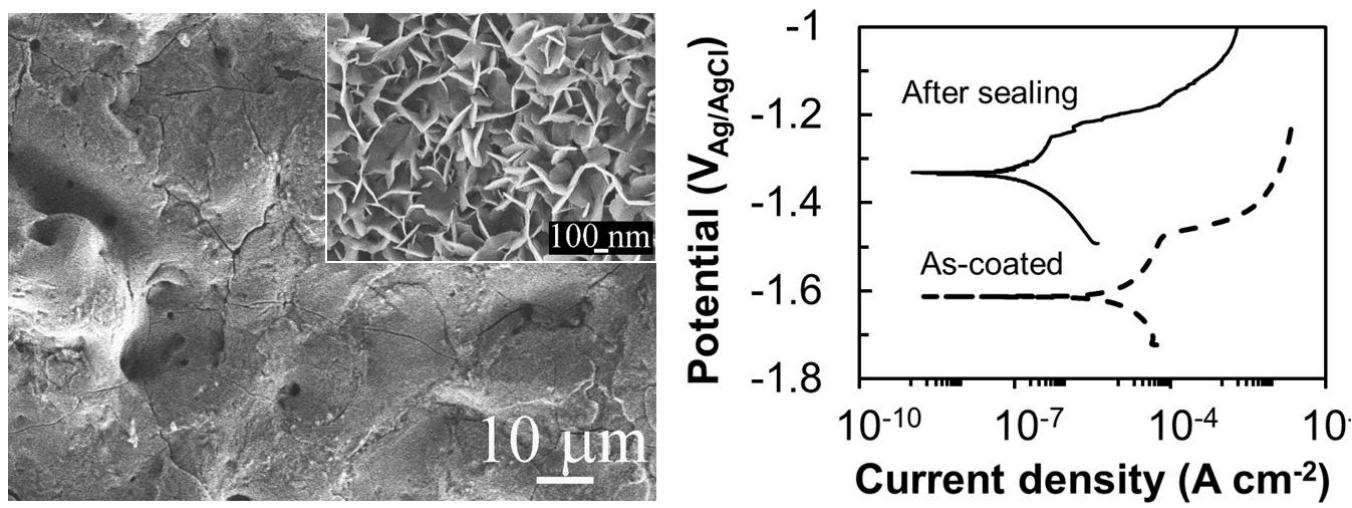

Figure 7 Effect of alkaline treatment on a) surface morphology and b) polarization curves of the PEO coated AZ61-2Ca specimen 


\section{CONCLUSION}

The corrosion behavior of PEO coated AZ61, AZ61-1Ca, and AZ61-2Ca specimens has been investigated. The following conclusions are made: (1) Surface investigation showed a similar PEO coating morphology of an eruption-like structure formed on all the alloy surfaces. The coating thickness was slightly greater for $\mathrm{Ca}$ containing alloys, but still in the same range between $10-20 \mu \mathrm{m}$; (2) The results of the electrochemical corrosion test in $0.9 \% \mathrm{NaCl}$ solution revealed that the coated AZ61, AZ61-1Ca, and AZ61-2Ca specimens exhibited very similar corrosion potential and current density. The effect of alloying element $\mathrm{Ca}$ on the polarization curve of the coated AZ61 alloys was negligible; (3) The proposed corrosion mechanism which occurred in the coated specimens involved initiation of thinning and penetration of the coating by the electrolyte, which led to the formation of a corrosion pouch at the metal-coating interface. The detachment of the coating was unavoidable as the corrosion pouch grew larger; and (4) Sealing of the coating in hot $\mathrm{NaOH}$ solution greatly enhanced the corrosion resistance of the coated AZ61-2Ca specimen. The apatite-forming ability of the sealed coating needs to be clarified in future work.

\section{ACKNOWLEDGEMENT}

We would like to acknowledge PDUPT DIKTI 2018 from the Ministries of Research, Technology, and Higher Education Republic of Indonesia for supporting this research. This work was also partly financed by a Grant-in-Aid for Scientific Research (B, 25289263) from the Japan Society for the Promotion of Science and the Light Metal Education Foundation of Japan.

\section{REFERENCES}

Anawati, A., Asoh, H., Ono, S., 2015. Enhanced Uniformity of Apatite Coating on a PEO Film Formed on AZ31 Mg Alloy by an Alkali Pretreatment. Surface and Coating Technology, Volume 272, pp. 182-189

Anawati, A., Asoh, H., Ono, S., 2017. Effects of Alloying Element Ca on the Corrosion Behavior and Bioactivity of Anodic Films Formed on AM60 Mg Alloys. Materials, Volume 10(11), pp. 1-16

Anawati, A., Gumelar, M.D., 2017. Characterization of Coatings Formed on AZX Magnesium Alloys by Plasma Electrolytic Oxidation. In: AIP proceedings of ISMM Conference

Atrens, A., Liu, M., Abidin, N.I.Z., 2011. Corrosion Mechanism Applicable to Biodegradable Magnesium Implants. Materials Science and Engineering: B, Volume 176(20), pp. 16091636

Ceschini, L., Morri, A., Angelini, V., Messieri, S., 2017. Fatigue Behaviour of Rare Earth Rich EV31A Mg Alloy: Influence of Plasma Electrolytic Oxidation. Metals, Volume 7(212), pp. $1-14$

DeGarmo, E.P., 2011. Materials and Processing in Manufacturing (11 ${ }^{\text {th }}$ ed.). Wiley \& Sons Inc.: USA

Gu, X.N., Li, N., Zhou, W.R., Zheng, Y.F., Zhao, X., Cai, Q.Z., Ruan, L., 2011. Corrosion Resistance and Surface Biocompatibility of a Microarc Oxidation Coating on a Mg-Ca Alloy. Acta Biomaterialia, Volume 7(4), pp. 1880-1889

Hornberger, H., Virtanen, S., Boccaccini, A.R., 2012. Biomedical Coatings on Magnesium Alloys-A Review. Acta Biomaterialia, Volume 8(7), pp. 2442-2455

Hussein, R.O., Northwood, D.O., Nie, X., 2013. The Effect of Processing Parameters and Substrate Composition on the Corrosion Resistance of Plasma Electrolytic Oxidation (PEO) Coated Magnesium Alloys. Surface and Coatings Technology, Volume 237, pp. 357-368 
Kannan, M.B., Raman, R.K.S., 2008. In Vitro Degradation and Mechanical Integrity of Calcium-Containing Magnesium Alloys in Modified-simulated Body Fluid. Biomaterials, Volume 29(15), pp. 2306-2314

Lunder, O., 1997. Corrosion Resistance of Cast Mg-Al Alloys. Corrosion Reviews, Volume 15(3-4), pp. 438-470

Massalski, T.B., 1990. Binary Alloy Phase Diagrams (2 ${ }^{\text {nd }}$ ed.), ASM: Materials Park, OH, USA

Muller, L., Muller, F.A., 2006. Preparation of SBF with Different $\mathrm{HCO}_{3}{ }^{-}$Content and its Influence on the Composition of Biomimetic Apatites. Acta Biomaterialia, Volume 2(2), pp. 181-189

Qudong, W., Wenzhou, C., Xiaoqin, Z., Yizhen, L., Wenjiang, D., Yanping, Z., Xiaoping, X., 2001. Effects of Ca Addition on the Microstructure and Mechanical Properties of AZ91 Magnesium Alloy. Journal of Materials Science, Volume 36(12), pp. 3035-3040

Rakoch, A.G., Khokhlov, V.V., Bautin, V.A., Lebedeva, N.A., Magurova, Y.V., Bardin, I.V., 2006. Model Concepts on the Mechanism of Microarc Oxidation on Metal Materials and the Control over this Process. Protection of Metals, Volume 42(2), pp. 158-169

Salashoor, M., Guo, Y., 2012. Biodegradable Orthopedic Magnesium-Calcium (MgCa) Alloys, Processing, and Corrosion Performance. Materials, Volume 5(1), pp. 135-155

Song, G., 2007. Control of Biodegradation of Biocompatible Magnesium Alloys. Corrosion Science, Volume 49(4), pp. 1696-1701

Srinivasan, P.B., Liang, J., Blawert, C., Stormer, M., Dietzel, W., 2010. Characterization of Calcium Containing Plasma Electrolytic Oxidation Coatings on AM50 Magnesium Alloy. Applied Surface Science, Volume 256(12), pp. 4017-4022

Witte, F., Hort, N., Vogt, C., Cohen, S., Kainer, K.U., Willumeit, R., Feyerabend, F., 2008. Degradable Biomaterials based on Magnesium Corrosion. Current Opinion in Solid State and Materials Science, Volume 12(5-6), pp. 63-72 